\title{
Review
}

\section{Review on Molecular Diagnosis of Cestode and Metacestode in Cattle}

\author{
Ziyad M. Bilal, DVM'*; Kedir S. Musa, DVM² \\ 'Department of Veterinary Medicine, Bedano Woreda Veterinary Clinic, East Hararghe, Ethiopia \\ ${ }^{2}$ Department of Veterinary Medicine, Haramaya University, College of Veterinary Medicine, P. O. Box I38, Dire Dawa, Ethiopia \\ *Corresponding author \\ Ziyad M. Bilal, DVM \\ Department of Veterinary Medicine, Bedano Woreda Veterinary Clinic, East Hararghe, Ethiopia; E-mail: ziyadmohammedbilal@gmail.com
}

\section{Article information}

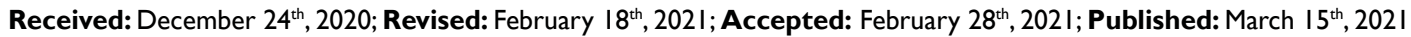

\section{Cite this article}

Bilal ZM, Musa KS. Review on molecular diagnosis of cestode and metacestode in cattle. Vet Med Open J. 202I; 6(I): 6-12. doi: 10.17। 140/VMOJ-6-I53

\section{ABSTRACT |}

Cestode infestations in animals are the most important parasite of livestock and humans because most of these parasites are zoonotic causing cysticercosis and hydatidosis in man and it causes economic and production losses in livestock. Diagnosis of Taenia Spp by microscopic observation lack sensitivity and specificity and detection by enzyme-linked immunosorbent assay (ELISA) technique form cross-reaction. The molecular diagnostic can be best to detect in adult and larval stage in definitive and intermediate host based on the amplification of deoxyribonucleic acid (DNA) of target gene with the primer using a different technique of polymerase chain reaction (PCR) such as multiplex PCR. Conventional PCR, real-time PCR, nested PCR, and PCR-restriction fragment length polymorphism (RFLP) are highly sensitive for the diagnosis of cestode and metacestode. Those diagnoses are used for differentiation of Taenia species and differentiation of Taenia and Echinococcus species. As compared to other diagnostic techniques most molecular methods have higher sensitivity and specificity but due to the relatively higher cost, few are commercially available. Most of the molecular diagnostic tests developed to date are generally applicable for laboratory research purposes. The developments in the genomic and proteomic analysis should be used for further understanding of parasite-animal host interaction to find additional targets for diagnosis.

\section{Keywords}

Cestode; Molecular test; Metacestode; Veterinary importance.

\section{Abbreviations}

Bp: Base pair; DNA: Deoxyribonucleic acid; ELISA: Enzyme-linked immunosorbent assay; gDNA: Genomic DNA; AMP: Loop-mediated isothermal amplification; NAD: Nicotinamide adenine dinucleotide; NADH: reduced form of NAD; PCR-REA: Polymerase chain reaction restriction enzyme analysis; PCR: Polymerase chain reaction; RFLP: Restriction fragment length polymorphism; rRNA: Ribosomal ribonucleic acid; REA: Restriction enzyme analysis; SSCP: Single-strand conformation polymorphism.
\end{abstract}

\section{INTRODUCTION}

$\mathrm{T}$ aeniidae is the largest family of flatworms (tapeworms) representing the order cyclophyllidae. It comprises numerous tapeworms with medical and veterinary importance. ${ }^{1}$ Tapeworms 4154(Cestode) of the family Taeniidae are transmitted from the definitive host such as carnivores to the intermediate hosts in1uding herbivores or omnivores and human beings via oral-fecal cycle. ${ }^{2}$ Taenia saginata and Taenia solium are the two taeniids of greatest economic and medical importance, causing bovine and porcine cysticercosis and taeniasis in humans. ${ }^{3}$ Echinococcosis, also called hydatidosis, is a zoonosis and in humans, it occurs as a result of infection by the larval (metacestode) stages of taeniid cestodes of the genus Echinococcus. It is characterized by long-term growth of Metacestode (larval) stages (hydatid cysts) in internal organs (mainly the liver and lungs) of intermediate host animals. ${ }^{4}$

The diagnosis of taeniasis is based on the detection of eggs by microscopic observation of fecal samples. This technique lacks both sensitivity and specificity since the eggs of most members of the family Taeniidae are morphologically indistinguishable. $^{5}$ Similarly, differentiation of T. solium and T. saginata is based on the morphological characteristic of the scolex or gravid proglottids. Recovery of scolices after treatment is uncommon for 
T. solium and in many cases, both the scolex and proglottids can be recovered only after special treatment. ${ }^{6}$ Detection of T.solium coproantigen by the enzyme-linked immunosorbent assay (ELISA) technique is used. The method is more sensitive than microscopy but cross-reacts with $T$. saginata.

Molecular approaches ${ }^{8}$ have attempted DNA differential diagnosis of taeniasis and cysticercosis by Multiplex PCR. Also, the presence of Metacestodes in animals is detecting by Multiplex PCR with cytochrome-c oxidase subunit 1 gene yield evident differential products unique for T. saginata, $T$. asiatica, and $T$. solium reviewed by. ${ }^{9}$

Molecular methods have also been used to determine species or genotypes of taeniids using 'pure' parasite DNA obtained from adult worms or Metacestodes from intermediate hosts. ${ }^{10}$ However, the potential of these approaches to identify or differentiate among species of taeniid eggs in faecal or environmental samples had not been evaluated. Several polymerase chain reaction (PCR) assays have been developed for the specific identification of E. multilocularis from such samples. ${ }^{11}$ The specific identification of E. granulosus eggs using monoclonal antibodies has been described but this method has not been utilized in further epidemiological studies. ${ }^{10}$ Therefore, the aim is to explore the developments of the molecular diagnostic test for cestodes and metacestodes of veterinary importance.

\section{CESTODES AND METACESTODES OF VETERINARY IMPORTANCE}

Cestodes are a large diverse group of platyhelminths that share two common features: as adults, they have an elongate body, and they lack an alimentary canal. Thus, adult tapeworms is almost invariably found in the definitive host intestine where they absorb nutrients directly across their tegument. ${ }^{12}$

\section{Taenia Solium/Cysticercus Cellulosae}

T. solium causes Cysticercosis in pigs and as for T. saginata, humans are the obligate definitive host. Unlike T. saginata, the eggs from the adult $T$. solium that are present in the faeces of a tapeworm carrier can infect not only the natural animal intermediate host (pigs) but are infective the person who might accidentally ingest the eggs. In humans the cysticerci may encyst in the brain, causing neurological disease. $^{13}$

\section{Taenia Saginata/Cysticercus Bovis}

Taeniasis is a cestode (tapeworm) infection of humans, with the adult phase of the worm residing in the intestine. Man is the definitive host of the cestode Taenia saginata (beef tapeworm). The intermediate host of the larval form of T. saginata is mainly domestic cattle. Beef tapeworm is transmitted when terminal segment (gravid proglottids), which each contain up to 100,000 eggs of $T$. saginata are detached from the segment chain (strobila), one by one and are passed in the feces of an infected person and the excreta is deposited in pastures or grazing area where the eggs are ingested by cattle. ${ }^{14}$ Cysticercus Bovis is caused by the metacestode stage of Taenia saginata, a zoonotic tapeworm of cattle and humans. Adult tapeworm develops in humans who consume undercooked beef infected with viable Metacestodes. ${ }^{15}$

\section{Taenia Hydatigena/Cysticercus Tenuicollis}

Cysticercus tenuicollis is the metacestode of canine tapeworm Taenia hydatigena, which has been reported in domestic and wild ruminants, pigs, monkeys. ${ }^{16}$ Metacestodes are found attached to the omentum, mesentery, and occasionally on the liver surface, however, unusual location of C.tenuicollis have been described as lungs, kidneys, brain, ovaries, uterine tubes, uterus, cervix, and vagina. An aberrant location of C.tenuicollis vesicle inside the chorioallantoic membrane of a goat foetus was reported. ${ }^{17}$ Pathogenicity of adult parasites is not high for the definitive hosts. However, a large number of developing cysticerci migrate contemporaneously in the liver of intermediate hosts, producing "hepatitis cysticercosa" a condition whose gross pathology resembles acute fasciolosis and which is often fatal. ${ }^{18}$

\section{Echinococcus/Hydatid Cyst}

Cystic Echinococcosis or cystic hydatidosis is a chronic helminthic zoonotic disease with a cosmopolitan distribution ${ }^{19}$ and is especially prevalent in the sheep-raising countries. The causative organism, the dog tapeworm Echinococcus granulosus is transmitted cyclically between canines and numerous herbivorous livestock animals, which can serve as intermediate hosts. In herbivorous animals and in people who become infected by accidentally ingesting E. granulosus ova, the cystic larval form (Hydatid Cyst) develops and can cause serious morbidity. ${ }^{20}$ Likewise, the disease often has severe consequences for health.

\section{DIAGNOSTIC TECHNIQUES FOR CESTODES AND METACESTODES}

Despite its many limitations, visual inspection of carcasses remains the most common method of diagnosing $T$. saginata cysticercosis. Studies showed the failure of detection during meat inspection as high as $80 \%{ }^{21}$ Diagnosis of cestodes and metacestodes is by physical imaging methods such as ultrasonography. However, the diagnostic potential of such techniques is sometimes limited by the atypical appearance of the visualized lesion that may also be insufficient in providing information about the involved species or about the viability of the parasite. ${ }^{22}$ Immunodiagnosis is a useful complementary diagnostic tool for the identification of infection and disease. ${ }^{23}$ Nevertheless, infections with different taeniid species and antigenic cross-reactivity between these related parasites and the low level of specific antibody response to infection problems with poor specificity and sensitivity of serological tests. ${ }^{24}$ To overcome the above diagnostic problem a molecular technique has been developed and adapted to advance laboratory diagnosis for cestode and metacestode. ${ }^{25}$

\section{MOLECULAR DIAGNOSIS OF CESTODES AND METACESTODES}

\section{Bovine and Porcine Cysticercosis}

The most widely used approach for DNA identification of Taenia 
taxa has been to target the nucleotide sequences of fragments of selected genes using pairs of concerned PCR primers.. ${ }^{15}$ The variable segment between the primers is PCR amplified for a particular Taenia sample and then directly sequenced. The $m t$ cox 1, nad1, cob, and $12 S r D N A$ genes, and nuclear $28 S r D N A$ and ITS1/ITS2 $r D N A$ have proven particularly valuable markers amenable to this approach. ${ }^{26}$ Given that different DNA markers have different rates of evolution and conserved sites, the results obtained from analyzing the same samples may be inconsistent. The mitochondrial cytochrome c oxidase subunit $2(\cos 2)$ gene has been widely used in studies of evolution and genetic diversity in many species. ${ }^{2}$

\section{Conventional Polymerase Chain Reaction}

Using primer designed to hybridize with the region of the $18 \mathrm{~S}$ and 28S ribosomal gene of DNA taken from T. solium (eggs, cysts, immature and mature worms) and T. saginata (eggs and mature worms). ${ }^{27}$ PCR detection of swine cysticercosis genomic DNA extracted from swine sera using different protocols showed higher specificity $(100 \%)$ with no cross-reaction to trichinellosis and toxoplasmosis. sensitivity was lower Cox1 PCR (23\%), T3/T4PCR $(32 \%)$, and Nested PCR (64\%) then ELISA-based detection of antibody from serum in the same study. ${ }^{28}$

\section{Restriction Enzyme Analysis}

DNA based differentiation of T. saginata and T. solium has been described and includes the use of probes. ${ }^{29}$ PCR with species-specific primers and PCR followed by restriction enzyme analysis (PCRREA). ${ }^{30}$ However, these methods require pure parasite DNA, which means that the DNA has to be extracted from a single proglottid and adequately cleaned, because these primers may amplify any eukaryotic DNA, causing cross-amplification. A few reports must describe the use of DNA-based techniques to differentiate T. solium from T. saginata from the fecal sample ${ }^{31}$ but they still lack sensitivity. Nonetheless, nowadays studies describe a; copro-PCR; for the simultaneous detection of the human tapeworm T. solium and T. saginata. Nkouawa ${ }^{32}$ reported stool PCR and loop-mediated isothermal amplification (LAMP) can distinguish between T. saginata and T. solium.

\section{Real-Time Polymerase Chain Reaction}

Newly developed a Real-time PCR to allow the sensitive and specific diagnosis of targets the COI gene of T. saginata by using TsagF oligonucleotide primers the technique yield $131 \mathrm{bp}$. When the results were compared with the reference A multiplex PCR the assay was less sensitive but offered the advantages of faster turnaround time and reduced contamination risk. ${ }^{15}$

\section{Multiplex Polymerase Chain Reaction}

As regards the identification of taeniid cestode parasites, multiplex PCR using taeniid species-specific and Taenia solium genotype specific-primers yielded differential products unique for T. saginata, T. asiatica, and Asian and American/African genotypes of T. solium with the molecular size of $827,269,984$, and 720 bp, respectively (Figure 1). ${ }^{33}$

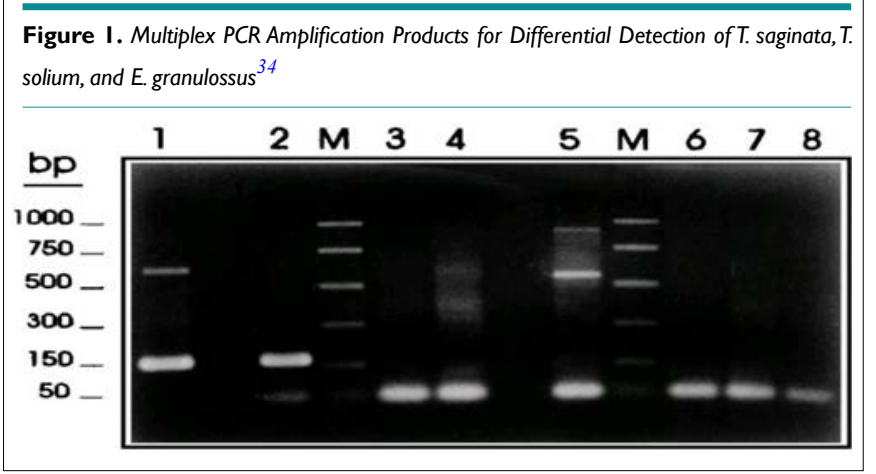

Gonzalez et $\mathrm{a}^{34}$ used Multiplex PCR for differential detection of T. saginata, T. solium, and E. granulossus based on the PTs7S35F1, PTs7S35F2, and PTs7S35R1 primers derived from the T. saginata genomic sequence HDP2. Samples of genomic DNA (1ng) from T. saginata (lane 1), T. solium (lane 2), T.taeniformis B (lane 3), T. taeniformis M (lane 4), E. granulosus (lane 8). Promega PCR molecular markers were used (lanes $\mathrm{M})$.

Samples of genomic DNA (1 ng) from T. saginata (lane 1), T. solium (lane 2), T.taeniformis B (lane3), T.taeniformis M (lane4), E.granulosus (lane 5), a calf (lane 6), and a human (lane 7) were amplified by the multiplex PCR based on the PTs7S35F1, PTs7S35F2, and Ts7S35R1 primers derived from the T.saginata genomic sequence HDP2. A negative control without DNA was also included (lane 8). The reactions were carried out as described in Materials and Methods. The amplification products were fractionated on a $2 \%$ agarose gel and were stained with ethidium bromide. Promega PCR molecular markers were used (lanes M).

\section{Nested-Polymerase Chain Reaction}

Mayta et $\mathrm{ll}^{35}$ reported Tso31 nested-PCR amplification using DNA extracted from different sources. Electrophoresis was performed using 5 micros (1) of the amplification product. Lane 1 and 13, 100-bp ladders; lane 2 to 8 , DNA from a contaminated sample with $100,50,20,10,5,2$, and 1 T.saginata proglottid; lane 9, DNA from a $T$. solium proglottid; lane 10 , DNA from a T. saginata proglottid; lane 11, DNA from a T. solium-positive stool sample; lane 12, DNA from a T. saginata-positive stool sample (Figure 2).

Figure 2. Nested PCR Amplification Products using DNA Extracted from Different Sources $^{35}$

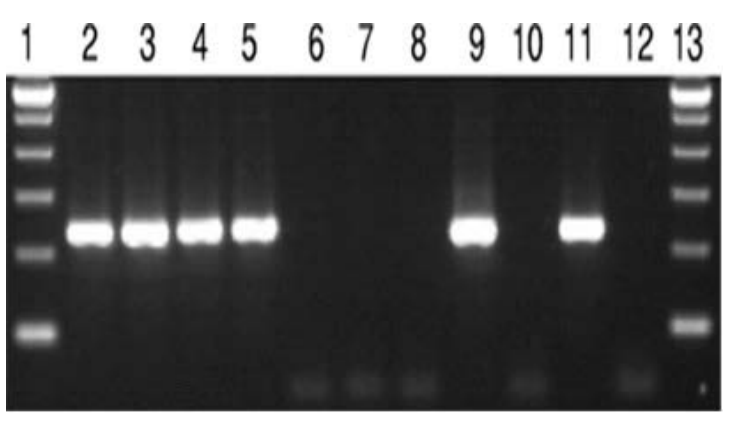




\section{Restriction Fragent Length Polymorphism}

Molecular approaches include restriction fragment length polymorphism (RFLP) analysis, PCR-linked RFLP analysis (PCR-RFLP), and direct comparison of PCR-amplified DNA sequences. ${ }^{36}$ Sequence data of mitochondrial $\mathrm{NADH}$ dehydrogenase subunit 1 (mt-ND 1) and cytochrome c oxidase subunit 1 (mtCO1) genes of genus Taenia (T. taeniaeformis, T. bydatigena, T. pisiformis, T. ovis, T. multiceps, T. solium, and the Asian Taenia) is available on gene bank. ${ }^{37}$

Geysen et $\mathrm{al}^{38}$ performed PCR-RFLP by amplification of two sequential rounds. In the first round, primers ITMTnR and TaenF were used to amplify 846 nucleotides. A second round was performed using ITM TnR and nTAE to amplify a sequence of 766 nucleotides. lanes 4, 6 to 18 and 20 to 26 display a band of approximately $800 \mathrm{bp}$ and are positive PCR results. Lane 3 and 5 are PCR-negative sample results. Lane 27 and 29 are negative control samples (Milli instead of extracted DNA) and lanes 28 and 30 are positive control samples (T. crassiceps DNA). Lanes 2 and 19 are DNA size markers (Figure 3).

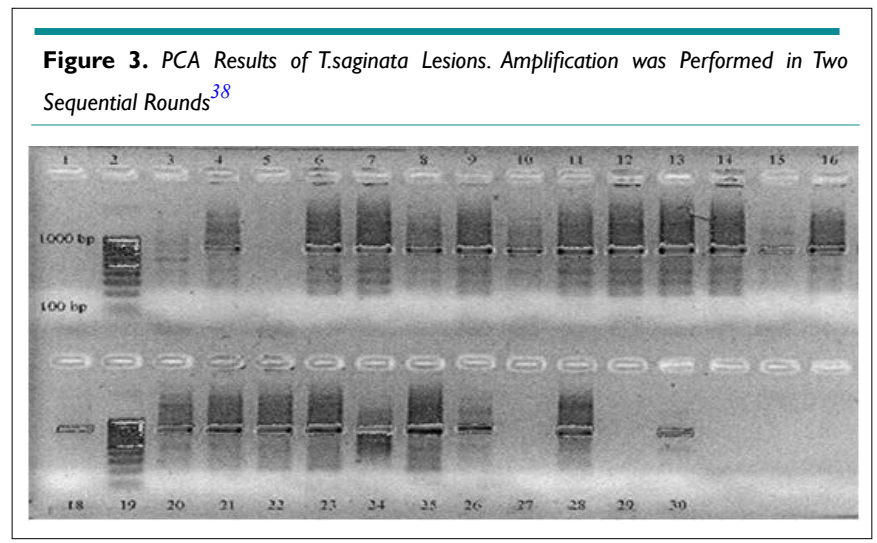

In the first round, primers ITMTnR (5CTCAATAATCGAGGGTGACGG3) and Taen F (5GTTTGCCACCTCGATGTTGACT) were used to amplify 846 nucleotides. A second round was performed using ITMT $\mathrm{n} \mathrm{R}$ and TAE (5CGTGAGCCAGGTCGGTTCTTAT3) to amplify a sequence of 766 nucleotides. Lane s 4, 6 to 18, and 20 to 26 display a band of approximately 800 bp and are positive PCR results. Lanes 3 and 5 are PCR-negative sample results. Lanes 27 and 29 are negative control samples (MilliQ instead of extracted DNA) and lanes 28 and 30 are positive control samples (T. crassiceps DNA). Lanes 2 and 19 are DNA size markers.

\section{Echinococcus/Hydatid Cyst}

Conventional polymerase chain reaction: Genetic variation in Echinococcus has been investigated using sequences from both the nuclear and mitochondrial genomes. The advent of the polymerase chain reaction (PCR) has provided a highly sensitive approach that is now widely used for Echinococcus identification purposes. ${ }^{39}$ Loop-mediated isothermal amplification assay primers (F3 and B3) for amplification mitochondrial NADH-1 gene of EG-complex Hydatid Cyst cattle strain of genotype 5(G5), was used as a target for using conventional PCR. Visualization of the 200-bp specific DNA PCR products on ethidium bromide-stained agarose gels. ${ }^{40}$

Conventional PCR targeting the E.granulosus specific DNA sequences of the NADH1 gene was performed on all serum, urine, and Hydatid Cyst fluid samples. The resultant $450 \mathrm{bp}$ amplification products were observed on a $1.2 \%$ agarose gel following electrophoresis. ${ }^{41}$ Boufana et $\mathrm{al}^{42}$ described conventional PCR assay based on the amplification of a fragment within the NADH dehydrogenase subunit 1 (ND1) mitochondrial gene were optimized for the detection of Echinococcushi quicus, Echinococcus granulosus, G1, and Echinococcus multiloclaris DNA-derived from parasite tissue or canid fecal samples.

Real-time polymerase chain reaction: A real-time PCR for the differentiation of the G1 and G2/G3 genotype of Echinococcus granulosus has been developed it has been suggested to offer several advantages over conventional PCR for the detection of parasitic infections, including increased sensitivity and specificity, reduced reaction time, and a quantitative estimate of the amount of bDNA in the sample (which May relate to both the infectiousness of the sample and the possible burden of infection. ${ }^{43}$

Restriction fragment length polymorphism: Azab et $\mathrm{al}^{44}$ developed restriction fragment length polymorphism (RFLP) analysis using conventional southern blotting. without loss of resolution or accuracy, by linking RFLP analysis with PCR targeting the nuclear ribosomal DNA (rDNA) internal transcribed spacer 1(ITS-1) region. The random amplified polymorphic (RAPD)-PCR(RAPDPCR) has also been used under careful conditions for distinguishing the four recognized Echinococcus species and genetically distinct forms of E. granulosus.

\section{Nested Polymerase Chain Reaction}

Complete sequences of the mitochondrial $(\mathrm{Mt})$ genomes of the horse and sheep strain of E. granulosus and E. multilocularis, and the availability of mt DNA sequences for several other E. granulosus genotypes, has provided additional genetic information that can be used for more in-depth strain characterization and taxonomic studies of these parasites. While Nested PCR on mitochondrial 12S rRNA gene shows $100 \%$ specificity when it was tested against E. multilocularis and E. granulosus isolates. ${ }^{45}$

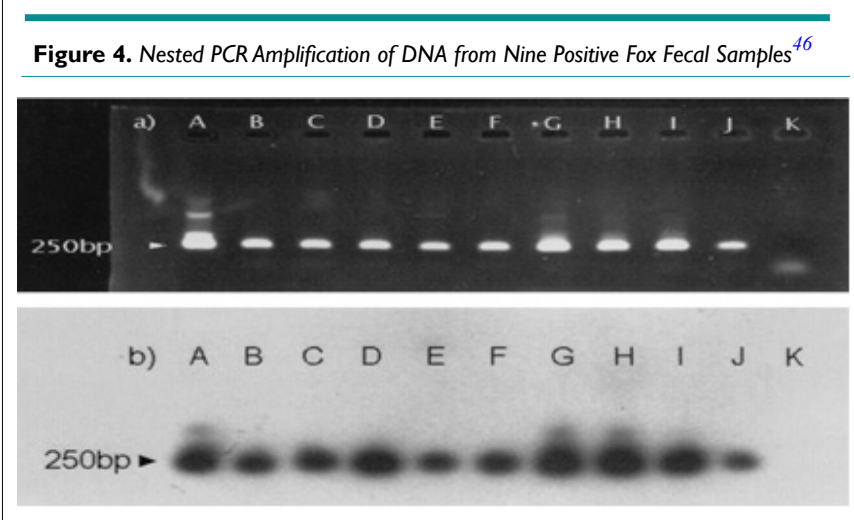


Nested PCR products from 60 positive fecal samples were randomly selected and underwent hybridization with the specific probe E. multi. 1. with all samples a hybridization signal was obtained. E. multilocularis metacestodes yielded the same characteristic band of $250 \mathrm{bp}$ (Figure 4).

Ethidium bromide staining of 101 of PCR products after $1.5 \%$ agarose gel electrophoresis showed the specific 250 bp band (a). The reaction products were analyzed by Southern transfer and hybridized with internal oligonucleotide E. multi. 1. labeled at the 5 end with digoxigenin(b). Lanes A, positive control; lanes B, C, D, E, F, G, H, I, and J, positive fox fecal samples; lanes $\mathrm{K}$, negative control. ${ }^{46}$

\section{Multiplex Polymerase Chain Reaction}

Stieger et $\mathrm{al}^{47}$ introduced Multiplex PCR amplify partial sequences of the mitochondrial genes for $\mathrm{NADH}$ dehydrogenase subunit 1 (nad 1) for detection of E. multilocularis, and the small subunit of ribosomal RNA (rRNA) for detection of E. granulosus and Taenia spp amplification products were visualized by $2 \%(\mathrm{~W} / \mathrm{V})$ agarose gel electrophoresis, and the 395,117, and 267 bp expected fragments were examined for the presence of E. multilocularis, E. granulosus, and Taenia spp, respectively. DNA isolation from Fox excrement was performed according to a novel procedure involving lysis in $\mathrm{KOH}$, phenol-chloroform extraction, and purification steps on a matrix (prep-A-Gene). The target sequence for amplification was the E. multilocularis $\mathrm{U} 1 \mathrm{snRNA}$ gene. ${ }^{48}$

Beiromvand et $\mathrm{al}^{48}$ reported by sequencing of $E$. multilocularis positive samples. Multiplex PCR showed 30 of 85 captured specimens $(35.3 \%)$ to be infected with E. multilocularis and $14(16.5 \%)$ infected with Taenia spp. by amplification of 395 bp fragment of nad1 and $267 \mathrm{bp}$ fragment of rRNA, respectively (Figure 5).

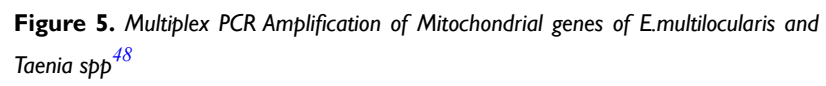

Figure 5. Multiplex PCR Amplification of Mitochondrial genes of E.multilocularis and Taenia $\operatorname{spp}^{48}$

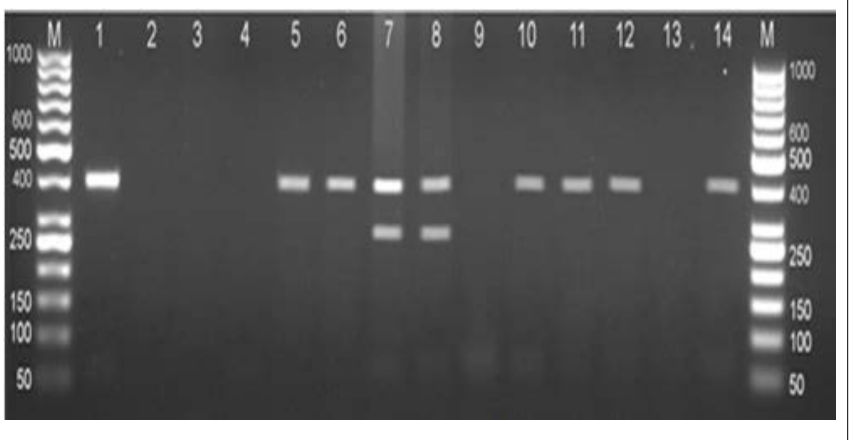

DNA extracted from the liver of Small mammals. Lane M, 50 bp DNA ladder (Fermentas; Cat No SM0373); Lane 1, positive control, a standard DNA of E. multilocularis (395 bp); Lane 2, negative control; Lane 5, 6, 10-12 E. multiloclaris; Lane 7 and 8, mixed infection of E. multilocularis (395 bp) and Taenia spp. (267 bp); Lane 3,4,9, and 13 negative samples.

\section{Single Strand Conformation Polymorphism}

Single-strand conformation polymorphism (SSCP) has been used to rapidly a large number of Echinococcus isolates. Another useful mutation scanning method is dideoxy fingerprinting (ddF), which is a hybrid between SSCP and conventional dideoxy sequencing. The technique has been used reproducibly for the direct display of sequence variation in the Cox1 gene to type and differentiate all of the Echinococcus genotypes examined. ${ }^{49}$ BartholomeiSantos et $\mathrm{al}^{50}$ isolate and characterize microsatellites using eight different oligonucleotides containing particular repeats as probes. Microsatellite DNA analyses have identified polymorphisms within the E. multilocularis endemic region.

\section{CONCLUSION}

In conclusion, the infection of cestode and metacestode of veterinary importance such as Echinococcosis and Cysticercosis contribute to a high-level of human and livestock production losses and morbidity. That is, Taenia saginata, Taenia solium, and Echinococcus cause production loss in bovine, sheep, goat, and pig respectively. As compared to other diagnostic techniques most molecular methods have higher sensitivity and specificity but due to the relatively higher cost, few are commercially available. Most of the molecular diagnostic tests developed to date are generally applicable for laboratory research purposes. The developments in the genomic and proteomic analysis should be used for further understanding of parasite-animal host interaction to find additional targets for diagnosis.

\section{CONFLICTS OF INTEREST}

The authors declare that they have no conflicts of interest.

\section{REFERENCES}

1. Qingling M, Guanglei W, Jun Q, Xinquan Z, Tianli L, Xuemei $\mathrm{S}$, et al. Prevalence of hydatid cysts in livestock animals in Xinjiang, China. Korean J Parasitol. 2014; 52(3): 331-334. doi: 10.3347/ kjp.2014.52.3.331

2. Rawson PD, Burton RS. Molecular evolution at the cytochrome oxidase subunit 2 gene among divergent populations of the intertidal copepod, Tigriopus californicus. J Mol Evol. 2006; 6: 753-764. doi: 10.1007/s00239-005-0074-7

3. Flisser A. Neurocysticercosis in Mexico. Parasitol Today. 1988; 4: 131-137. doi: 10.1016/0169-4758(88)90187-1

4. Oryan A, Goorgipour S, Moazeni, M, Shirian S. Abattoir prevalence, organ distribution, public health and economic importance of major metacestodes in sheep, goats and cattle in Fars, southern Iran. Trop Biomed. 2012; 3: 349-359.

5. McManus DP, Gray DJ, Zhang W, Yang Y. Diagnosis, treatment, and management of echinococcosis. 2012; 344: 3866.

6. Jeri CRH, Gilman AG, Lescano H, Mayta ME, Ramirez AE, 
Gonzalez R, et al. Species identification after treatment for human taeniasis. Lancet. 2004; 363: 949-950. doi: 10.1016/S01406736(04)15791-7

7. Deplazes P, Eckert J, Pawlowski ZS, Machowska L, Gottstein B. An enzyme-linked immunosorbent assay for diagnostic detection of Taenia saginata copro antigens in humans. Trans $\mathrm{R}$ Soc Trop Med Hyg. 1991; 85: 391-396. doi: 10.1016/0035-9203(91)90302-f

8. Yamasaki H, Allan JC, Sato MO, Nakao M, Sako Y, Nakaya K, et al. DNA differential diagnosis of taeniasis and cysticercosis by multiplex PCR. J Clin Microbiol. 2004b; 42: 548-553. doi: 10.1128/ jcm.42.2.548-553.2004

9. Kemal J, Alemu S, Yimer M, Terefe G. Immunological and molecular diagnostic tests for cestodes and metacestodes: Review. World Applied Sciences Journal. 2015; 33: 1867-1879. doi: 10.5829/ idosi.wasj.2015.33.12.101101

10. Craig PS, Macpherson CNL, Nelson GS. The identification of eggs of by immunofluorescence using a specific anti-oncospheral monoclonal antibody. Am J Trop Med Hyg. 1986; 1: 152-158. doi: 10.4269/ajtmh.1986.35.152

11. Mathis A, Deplazes P. Copro-DNA tests for diagnosis of animal taeniid cestodes. Parasitol Int. 2006; 55 Suppl: S87-90. doi: 10.1016/j.parint.2005.11.012

12. Hoberg E. Taenia tapeworms: Their biology, evolution and socioeconomic significance. Microbes Infect. 2002; 4: 859-866. doi: 10.1016/s1286-4579(02)01606-4

13. Gemmell M, Matyas Z, Pawlowski Z, Soulsby EJ, Larralde C, Nelson GS, et al. Guidelines for surveillance, prevention and control of taeniasis/cysticercosis (No. VPH/83.49). Web site. https:// apps.who.int/iris/handle/10665/66403. 1983. Accessed December 23, 2020.

14. Silva VC, Costa-Cruz JM. A glance at Taenia saginata infection, diagnosis, vaccine, biological control and treatment. Infect Disord Drug Targets. 2010; 10: 313-321. doi: 10.2174/187152610793180894

15. Cuttell L, Owen H, Lew-Tabor AE, Traub RJ. Bovine cysticercosis--development of a real-time PCR to enhance classification of suspect cysts identified at meat inspection. Vet Parasitol. 2013; 194: 65-69. doi: 10.1016/j.vetpar.2013.02.018

16. Kassai T. Veterinary Helminthology. Oxford, USA: Reed Educational and Professional Publishing; 1999: 260.

17. Payan-Carreira R, Silva F, Rodrigues M, dos Anjos Pires M. Cysticercus tenuicollis vesicle in fetal structures: Report of a case. Reprod Domest Anim. 2008; 6: 764-766. doi: 10.1111/j.14390531.2007.01014.x

18. Urguhart G, Armour J, Duncan J, Dunn A, Jennings F. Veterinary helminthology. Vet Parasitol. 1996; 2: 35-38.
19. Eckert JP, Deplazes PS, Gemmell CM, Gottstein B, Heath DJ, Jenkins, Kamiya M, Lightowlers M. Echinococcosis in animals: clinicalaspects, diagnosis and treatment. Paris,France: World Organisation for Animal Health; 2001: 7299.

20. Eckert J, Conraths FJ, Tackmann K. Echinococcosis:an emerging or reemerging zoonosis. Int J Parasitol. 2000; 30: 1283-1294. doi: 10.1016/s0020-7519(00)00130-2

21. Eddi, C., Nari, A. and Amanfu, W. Taenia solium cysticercosis/taeniosis: potential linkage with FAO activities; FAO support possibilities. Acta Tropica. 2003; 87: 145-148. doi: 10.1016/s0001706x $(03) 00037-8$

22. Thompson RCA, McManus DP. Towards a taxonomic revision of the genus Echinococcus. Trends Parasitol. 2002; 18: 452-457. doi: 10.1016/s1471-4922(02)02358-9

23. Zhang W, Li J, McManus DP. Concepts in immunology and diagnosis of hydatid disease. Clin Microbiol Rev. 2003; 16: 18-36. doi: 10.1128/cmr.16.1.18-36.2003

24. Ogunremi O, Benjamin J. Development and field evaluation of a new serological test for Taenia saginatacysticercosis. Vet Parasitol. 2010; 169: 93-101. doi: 10.1016/j.vetpar.2009.12.014

25. Siles Lucas MM, Gottstein BB. Molecular tools for the diagnosis of cystic and alveolar echnococcosis. Trop Med Int Health. 2001; 6: 463-475. doi: 10.1046/j.1365-3156.2001.00732.x

26. Eom KS, Jeon HK, Kong Y, Hwang UW, Yang Y, Li X., et al. Identification of Taenia asiatica in China: Molecular, morphological, and epidemiological analysis of a Luzhai isolate. Vet Parasitol. 2002; 88: 758-764. doi: 10.1645/0022-3395(2002)088[0758:IOTA$\mathrm{IC}] 2.0 . \mathrm{CO} ; 2$

27. Mayta HA, Talley RH, Gilman J, Jime'nez M, Verastegui M, Ruiz HH, et al. Differentiating Taenia solium and Taenia saginata infections by simple hematoxylin-eosin staining and PCR restriction enzyme analysis. J Clin Microbiol. 2000; 38: 133-137.

28. Ramahefarisoa RM, Rakotondrazaka M, Jambou R, Carod JF. Comparison of ELISA and PCR assays for the diagnosis of porcine cysticercosis. Vet Parasitol. 2010; 173: 336-339. doi: 10.1016/j. vetpar.2010.05.002

29. Harrison LJS, Delgado J, Parkhouse RME. Differential diagnosis of Taenia saginata and Taenia solium with DNA probes. Parasitology. 1990; 100: 459-461. doi: 10.1017/s0031182000078768

30. Yamasaki H, Nakao M, Sako Y, Nakaya K, Sato MO, Ito A. Mitochondrial DNA diagnosis for taeniasis and cysticercosis. Parasitol Int. 2006; 55: 81-85. doi: 10.1016/j.parint.2005.11.013

31. Nunes CM, Dias AK, Dias FE, Aoki SM, dePaula HB, Lima LG, et al. Taenia saginata: Differential diagnosis of human taeniasis by polymerase chain reaction restriction fragment length polymorphism assay. Exp Parasitol. 2005; 110: 412-415. doi: 10.1016/j. 
exppara.2005.03.008

32. Nkouawa A, SakoY, LiT, Chen X, Wandra T, Swastika IK, et al. Evaluation of aloop mediate disothermal amplification method using fecal specimens for differential detection of Taenia species from humans. J Clin Microbiol. 2010; 48: m 3350-3352. doi: 10.1128/JCM.00697-10

33. Yamasaki H, Allan JC, Sato MO, Nakao M, Sako Y, Nakaya K, et al. Multiplex PCR diagnosis for taeniasis and cysticercosis. Southeast Asian J Trop Med Public Health. 2004a; 35: 275-279.

34. González LM, Montero E, Harrison LJ, Parkhouse RME, Garate T. Differential diagnosis of Taenia saginata and Taenia solium infection by PCR. J Clin Microbiol. 2000; 38: 737-744. doi: 10.1128/ JCM.38.2.737-744.2000

35. Mayta H, Gilman RH, Prendergast E, Castillo JP, Tinoco YO, Garcia HH, et al. Nested PCR for specific diagnosis of Taenia solium taeniasis. J Clin Microbiol. 2008; 46: 286-289. doi: 10.1128/ JCM.01172-07

36. Jia WZ, Yan HB, Guo AJ, Zhu XQ, Wang YC, Shi WG, et al. Complete mitochondrial genomes of Taenia multiceps, T. hydatigena and T. pisiformis: Additional molecular markers for a tapeworm genus of human and animal health significance. BMC Genomics. 2010; 11: 447. doi: 10.1186/1471-2164-11-447

37. Geysen D, Kanobana K, Victor B, Rodriguez-Hidalgo R, De Borchgrave J, Brandt J, et al. Validation of meat inspection results for Taenia saginata cysticercosis by PCR- restriction fragment length polymorphism. J Food Prot. 2007; 1: 236-240. doi: 10.4315/0362-028x-70.1.236

38. Dinkel A, Njoroge EM, Zimmermann A, Wälz M, Zeyhle E. A PCR system for detection of species and genotypes of the Echinococcus granulosus-complex, with reference to the epidemiological situation in eastern Africa. Int J Parasitol. 2004; 34: 645-653. doi: 10.1016/j.ijpara.2003.12.013

39. Ahmed ME, Eldigail MH, Elamin FM, Ali IA, Grobusch MP, Aradaib IE. Development and evaluation of real-time loop-mediated isothermal amplification assay for rapid detection of cystic echinococcosis. BMC Vet Res. 2016; 12(1): 202. doi: 10.1186/ s12917-016-0809-2

40. Sambrook J, Fritsch EF, Maniatis T. Molecular Cloning: A Laboratory Manual. $2^{\text {nd }}$ ed. New York, USA: Cold Spring Harbor Laboratory Press; 1989: 76-79.
41. Boufana B, Qiu J, Chen X, Budke CM, Campos-Ponce M, Craig PS. First report of Echinococcus shiquicus in dogs from eastern Qinghai-Tibet plateau region, China. Acta Tropica. 2013; 127(1): 21-24. doi: 10.1016/j.actatropica.2013.02.019

42. Maurelli MP, Rinaldi L, Capuano F, Perugini AG, Cringoli G. Development of a real-time PCR for the differentiation of the G1 and G2/G3 genotypes of Echinococcus granulosus. Parasitology. 2009; 1: 255-259. doi: 10.1007/s00436-009-1388-y

43. Azab M, Bishara S, Helmy H, Oteifa N, El-Hoseiny L, Ramzy $\mathrm{R}$, et al. Molecular characterization of option human and animal Echinococcus granulosus, isolates by RAPDPCR technique. $J$ Egypt Soc Parasitol. 2004; 34: 83-96.

44. McManus DP, Thompson RC. Molecular epidemiology of cystic echinococcosis. Parasitology. 2003; 127: 37-51. doi: 10.1017/ s0031182003003524

45. Dinkel A, von Nickisch-Rosenegk M, Bilger B, Merli M, Lucius $\mathrm{R}$, Romig T. Detection of Echinococcus multilocularis in the definitive host: coprodiagnosis by PCR as an alternative to necropsy. J Clin Microbiol. 1998; 36: 1871-1876. doi: 10.1128/JCM.36.7.18711876.1998

46. Stieger C, Hegglin D, Schwarzenbach G, Mathis A, Deplazes P. Spatial and temporal aspects of urban transmission of Echinococcus multilocularis. Parasitology. 2002; 124: 631-640. doi: 10.1017/ s0031182002001749

47. Bretagne S, Guillou JP, Morand M, Houin R. Detection of Echinococcus multilocularis DNA in fox faeces using DNA amplification. Parasitology. 1993; 106: 193-199. doi: 10.1017/ s0031182000074990

48. Beiromvand M, Akhlaghi L, Massom SHF, Meamar AR, Darvish J, Razmjou E. Molecular identification of Echinococcus multilocularis infection in small mammals from Northeast, Iran. PLoS Negl Trop Dis. 2013; 7: 2313. doi: 10.1371/journal.pntd.0002313

49. Gasser RB, Zhu XQ. Sequence-based analysis of enzymatically amplified DNA fragments by mutation detection techniques. Parasitology. 1999; 15: 462-465. doi: 10.1016/s0169-4758(99)01536-7

50. Bartholomei-Santos ML, Heinzelmann LS, Oliveira RP, Chemale G, Gutierrez AM, Kamenetzky L, et al. Isolation and characterization of microsatellites from the tapeworm Echinococcus granulosus. Parasitology. 2003; 126: 599-605. 